\title{
Obesity and central obesity
}

\section{Nia Kurniati}

Department of Child Health, Faculty of Medicine, Universitas Indonesia, Cipto Mangunkusumo Hospital, Jakarta, Indonesia

Overweight and obesity are condition that are associated with increased morbidity and mortality of chronic diseases and health problems, including cardiovascular disease, type II diabetes, musculoskeletal disorders, especially osteoarthritis and certain site-specific cancers, including colorectal and breast cancer. Overweight and obesity is defined as having a body mass index (BMI) $>25 \mathrm{~kg} / \mathrm{m}$ (BMI; obtained by dividing the individual's weight in kilograms by the squared of height in meters). This measurement is easy to obtain, reproducible, and widely accepted not only for epidemiological purpose and physician use a BMI data to manage their patient in daily clinical setting. There are different categories from overweight to morbid obesity based on BMI, for different gender and age. There is also a different standard BMI for children; age and sex matched should be considered before diagnosing overweight or obese based on their percentile position.

Epidemiological studies have used a BMI as the chosen method to measure the body size. World Health Organization (WHO) stated that by 2016 around $39 \%$ of adults were overweight and $13 \%$ adult were obese, with women population has slightly higher prevalence. ${ }^{1}$ Mortality of non-communicable disease (NCD) related to overweight and obesity is increased globally, even in developing world where malnourishment is still become a problem. The prevalence of obesity and central obesity in the Indonesian adult population according to National Health Census in 2007 were $23.1 \%$ and $28 \%$, according to recent publication. ${ }^{2}$ The prevalence of both obesity criteria are higher in females than males. This phenomenon has driven a global campaign to develop a prevention of overweight with an introduction of healthy diet and promotion of physical activity.

Determining the best method for quantifying body fat is important in selecting population who will require a specific intervention to lower NCD risk. The concept of central obesity seemed to have a better predicting a degree of fatness and eventually metabolic problem. Fat distribution in abdominal obesity has worsened the correlation with metabolic problem. ${ }^{3}$ Central obesity using waist circumference (WC) or waist to hip ratio (WHR) has been suggested to be better in predicting CVD risk individually than using only a BMI (obesity). ${ }^{4}$ Different pattern of central obesity between man and woman is recognized as the android pattern; thus increase waist circumference is seen more in men. However, an advanced age in woman also change the obesity pattern. Currently, the WHO recognizes that WC between $94.0-101.9 \mathrm{~cm}$ in men and 80.0-87.9 $\mathrm{cm}$ in women and WHR 40.8 and 40.9 in women and men, respectively, correspond with the BMI overweight range $25-29.9 \mathrm{~kg} / \mathrm{m}$.

The Emerging Risk Factors Collaboration $(2011)^{5}$ stated that incorporating a waist circumference information in prediction models

Table 1. Combined recommendations of BMI and waist circumference cut-off points made for overweight or obesity, and association with co-morbidities risk. ${ }^{1}$

\begin{tabular}{|c|c|c|c|}
\hline Classification & $\begin{array}{c}\text { BMI } \\
\left(\mathrm{kg} / \mathrm{m}^{2}\right)\end{array}$ & \multicolumn{2}{|c|}{ Risk of co-morbidities } \\
\hline & & \multicolumn{2}{|c|}{ Waist circumference } \\
\hline & & $\begin{array}{l}<90 \mathrm{~cm} \\
(\mathrm{men})\end{array}$ & $\begin{array}{c}\geq 90 \mathrm{~cm} \\
(\mathrm{men})\end{array}$ \\
\hline & & $\begin{array}{c}<80 \mathrm{~cm} \\
\text { (women) }\end{array}$ & $\begin{array}{c}\geq 80 \mathrm{~cm} \\
\text { (women) }\end{array}$ \\
\hline Underweight & $<18.5$ & $\begin{array}{l}\text { Low (but } \\
\text { increased } \\
\text { risk of other } \\
\text { clinical } \\
\text { problems) }\end{array}$ & Average \\
\hline Normal & $18.5-22.9$ & Average & Increased \\
\hline Overweight & $\geq 23$ & & \\
\hline At risk & $23-24.9$ & Increased & Moderate \\
\hline Obese I & $25-29.9$ & Moderate & Severe \\
\hline Obese II & $\geq 30$ & Severe & $\begin{array}{c}\text { Very } \\
\text { severe }\end{array}$ \\
\hline
\end{tabular}


did not increase the prognostic value provided by BMI if they have other information such as circumference information in prediction models did not increase the prognostic value provided by BMI if they have other information such as a history of diabetes, high blood pressure, and high cholesterol levels. However, the study also showed that for a certain BMI category, subgroups of waist circumference or WHR were associated with an increased mortality risk.

Other studies demonstrated that a measure of central obesity such as waist-to-hip ratio, waistto-height ratio, ${ }^{6,7}$ or waist circumference alone may provide an additional information beyond a BMI on mortality risk among middle-aged adults; there is no adjustment for obesity-related cardiovascular risk factors. ${ }^{8,9}$ Moreover, a study has also shown that measures of central obesity are more strongly associated with total and cardiovascular disease death than BMI. ${ }^{9}$

In this issue of Medical Journal of Indonesia (MJI), Harbuwono et $\mathrm{al}^{2}$ provide the obesity data not only using BMI measurement, but also waist circumference in relation to several prognostic factor of NCD. The main finding was that one-fourth Indonesian population fell into obesity category, even in 10-year old survey data. The message is clear that given the pattern of increased obesity globally, Indonesian epidemiological data should show more than $25 \%$ obese population. As a physician, we should always spend time to consider an obesity and its related problem in our population.

\section{REFERENCES}

1. World Health Organization. The Asia-Pacific perspective: redefining obesity and its treatment. 2000.

2. Harbuwono DS, Pramono LA, Yunir E, Subekti I. Obesity and central obesity in Indonesia: evidence from a national health survey. Med J Indones. 2018;27(2):114-20.

3. Wijga AH, Scholtens S, Bemelmans WJ, de Jongste JC, Kerkhof M, Schipper M, et al. Comorbidities of obesity in school children: a cross-sectional study in the PIAMA birth cohort. BMC Public Health. 2010;10:184.

4. Sahakyan KR, Somers VK, Rodriguez-Escudero JP, Hodge DO, Carter RE, Sochor O, et al. Normal-weight central obesity: implications for total and cardiovascular mortality. Ann Intern Med. 2015;163(11):827-35.

5. The Emerging Risk Factors Collaboration. Separate and combined associations of body-mass index and abdominal adiposity with cardiovascular disease: collaborative analysis of 58 prospective studies. Lancet. 2011;377(9771):1085-95.

6. Ashwell M, Mayhew L, Richardson J, Rickayzen B. Waist-to-height ratio is more predictive of years of life lost than body mass index. PloS one. 2014;9(9):e103483.

7. Cornier MA, Despres JP, Davis N, Grossniklaus DA, Klein S, Lamarche B, et al. Assessing adiposity: a scientific statement from the American Heart Association. Circulation. 2011;124(18):1996-2019.

8. Kahn HS, Bullard KM, Barker LE, Imperatore G. Differences between adiposity indicators for predicting all-cause mortality in a representative sample of United States non-elderly adults. PloS one. 2012;7(11):e50428.

9. Coutinho T, Goel K, Correa de Sa D, Carter RE, Hodge DO, Kragelund C, et al. Combining body mass index with measures of central obesity in the assessment of mortality in subjects with coronary disease: role of "normal weight central obesity". J Am Coll Cardiol. 2013;61(5):553-60.

pISSN: 0853-1773•eISSN: 2252-8083•https://doi.org/10.13181/mji.v27i2.3014• Med J Indones. 2018;27:69-70

Corresponding author: Nia Kurniati

niawidj@gmail.com

Copyright @ 2018 Authors. This is an open access article distributed under the terms of the Creative Commons Attribution-NonCommercial 4.0 International License (http://creativecommons.org/licenses/by-nc/4.o/), which permits unrestricted non-commercial use, distribution, and reproduction in any medium, provided the original author and source are properly cited. 